\title{
Correction to: Development of a custom next-generation sequencing panel for the determination of bladder cancer risk in a Tunisian cohort
}

\author{
Imen Hemissi ${ }^{1}\left[\begin{array}{l}10 \\ \text { S Sami Boussetta }\end{array}{ }^{2} \cdot\right.$ Hamza Dallali $^{3} \cdot$ Faycel Hellal ${ }^{4} \cdot$ Geoffroy Durand $^{5} \cdot$ Catherine Voegele $^{5}$. \\ Haroun Ayed ${ }^{6}$. Selim Zaghbib ${ }^{6} \cdot$ Zeineb Naimi $^{7} \cdot$ Mouna Ayadi $^{7} \cdot$ Mohamed Chebil $^{6}$ (D) James Mckay ${ }^{5}$ (1) . \\ Florence Le Calvez-Kelm ${ }^{5}$ (i) Slah Ouerhani ${ }^{1}$ (])
}

Published online: 2 January 2022

(c) Springer Nature B.V. 2021

\section{Correction to: Molecular Biology Reports https://doi.org/10.1007/s1 1033-021-06951-4}

Unfortunately, one of the co-authors' last names, Florence Le Calvez Kelm, was misspelled in the original version of this article. Initially, the production process was started according to the original manuscript, which had Florence Le Calvez-Klem spelled incorrectly.

The original article has been corrected.

The original article can be found online at https://doi.org/10.1007/ s11033-021-06951-4.

Slah Ouerhani

slah_mekni@yahoo.fr

Imen Hemissi

imenhemissi@gmail.com

Sami Boussetta

sami-boussetta@hotmail.com

Hamza Dallali

hamza.dallali92@gmail.com

Faycel Hellal

hellalf@yahoo.fr

Geoffroy Durand

geoffroy.durand@med.lu.se

Catherine Voegele

VoegeleC@iarc.fr

Haroun Ayed

ayedharoun@yahoo.fr

Selim Zaghbib

selim.zaghbib@gmail.com

Zeineb Naimi

zeinebnaimi89@gmail.com

Mouna Ayadi

mounaayadi28@gmail.com
Publisher's Note Springer Nature remains neutral with regard to jurisdictional claims in published maps and institutional affiliations.

Mohamed Chebil

mohamed.chebil.uro@gmail.com

James Mckay

mckyj@iarc.fr

Florence Le Calvez-Kelm

LeCalvezF@iarc.fr

1 Laboratory of Proteins Engineering and Bioactive Molecules (LIP-MB), INSAT, National Institute of Applied Sciences and Technology of Tunis, University of Carthage, Tunis, Tunisia

2 Laboratory of Genetics, Immunology and Human Pathology, Faculty of Sciences of Tunis, Tunis, Tunisia

3 Pasteur Institute of Tunis, Tunis, Tunisia

4 National Institute of Applied Sciences and Technology of Tunis, University of Carthage, Tunis, Tunisia

5 Centre International de Recherche sur le Cancer CIRC/International Agency for Research on Cancer IARC, Lyon, France

6 Urology Department, Charles Nicolle Hospital, Tunis, Tunisia

7 Medical Oncology Department, Saleh Azaiez Institute, Tunis, Tunisia 